\title{
Evaluation of HbA1c in the Diagnosis of Diabetes
}

\author{
Jasvinder Kaur Bhatia ${ }^{1}$ and Jagdeep Singh Bhatia ${ }^{2 *}$ \\ ${ }^{1}$ Department of Pathology, Armed Forces Medical college Pune, India \\ ${ }^{2}$ Department of Anaesthesia, Command Hospital, Southern Command, Pune, India
}

\begin{abstract}
Background: Diabetes has become a major health problem in India with the largest number of diabetic patient burden in the world. It is estimated that, this disease will assume epidemic proportions during the first quarter of the 21 st century and by the year $2025,>75 \%$ of people with diabetes will reside in developing countries, as compared with $62 \%$ in 1995 . We evaluated the clinical utility of HbA1c as the base line investigation along with plasma glucose estimation in hospitalized patients for diagnosis of diabetes mellitus.
\end{abstract}

Methods: A total of 400 patients of more than 25 yrs were tested. All the patients were evaluated by a random plasma glucose estimation, plasma glucose fasting and $2 \mathrm{~h}$ after $75 \mathrm{~g}$ of glucose and $\mathrm{HbA} 1 \mathrm{c}$.

Result: Fasting plasma levels varied from $82 \mathrm{mg} / \mathrm{dl}$ to $216 \mathrm{mg} / \mathrm{dl} \mathrm{A}$ total of 11 patients had plasma glucose values in the diabetic range (>126mg/dl) Plasma glucose in these patients ranged from 129 to $216 \mathrm{mg} / \mathrm{dl}$. Patients with diabetes had higher HbA1c levels than subjects without diabetes. We found that an $\mathrm{HbAlc}$ value $=>6.5 \%$ was $100 \%(11 / 11)$ specific for the diagnosis of diabetes.

Conclusion: HbAlc correlated well with fasting plasma glucose values. In clinical settings, this test would be preferred as a first line test for diagnosis of diabetes in our country as it is convenient for the patient.

Keywords: Diabetes mellitus, HbA1c, Plasma Glucose Measurement.

\section{Introduction}

Diabetes has become a major health problem in India with the largest number of diabetic patient burden in the world. It is estimated that, this disease will assume epidemic proportions during the first quarter of the 21 st century and by the year $2025,>75 \%$ of people with diabetes will reside in developing countries, as compared with $62 \%$ in 1995 . The countries with the largest number of people with diabetes are, and will be in the year 2025, India, China, and the U.S (1). In Indians, onset of diabetes occurs at a younger age and gives ample time for development of chronic vascular complications thus adding to the economic burden (2)

It becomes important that we diagnose the disease early to initiate treatment at the earliest. Standard test for diagnosis of diabetes are the plasma glucose fasting and post $2 \mathrm{~h}$ glucose plasma glucose estimations (3). International expert committee has recommended HbAlc for the diagnosis of diabetes mellitus as it correlates well with fasting plasma glucose (4).

How useful this is in our settings needs to be evaluated. We evaluated the clinical utility of $\mathrm{HbAlc}$ as the base line investigation along with plasma glucose estimation in hospitalized patients for diagnosis of diabetes mellitus.

\section{Materials and Methods}

The sample population consisted of randomly selected patients being admitted in our hospital for varying diagnoses. There was no history of diabetes in these patients but they had one or more risk factors. All persons with a family history of diabetes and/or high blood pressure and lipid abnormalities were included. Children and pregnant women were excluded from the study. A total of 400 patients of more than $25 \mathrm{yrs}$ were tested. All the patients were evaluated by a random plasma glucose estimation, plasma glucose fasting and $2 \mathrm{~h}$ after $75 \mathrm{~g}$ of glucose and HbAlc.

The plasma glucose levels were estimated using Glucose Oxidase method. Each run included assayed normal and abnormal controls. Hbalc was estimated using the NycoCard reader, (NGSP certified method). With a sample volume of $5 \mu \mathrm{L}$, on anticoagulated venous blood (EDTA). This test is based on Boronate affinity test principle with no interference from $\mathrm{Hb}$ variants like $\mathrm{HbC}, \mathrm{HbE}, \mathrm{HbF}, \mathrm{HbJ}$ and $\mathrm{HbS}$. Those subjects in whom diabetes were diagnosed by fasting plasma glucose, repeat test was done on another occasion to confirm the diagnosis(2).

\section{Result}

A total of 400 patients were evaluated. Males constituted $65 \%$ of the patients. Age of the patients ranged from 25 to 79 years. Fasting and post prandial blood glucose criteria were as per the guidelines of WHO. For HbAlc, We used a cut off value of $6.5 \%$ for the diagnosis of diabetes mellitus (4). Fasting plasma levels varied from 
$82 \mathrm{mg} / \mathrm{dl}$ to $216 \mathrm{mg} / \mathrm{dl} \mathrm{A}$ total of 11 patients had plasma glucose values in the diabetic range $(>126 \mathrm{mg} / \mathrm{dl})$ Plasma glucose in these patients ranged from 129 to $216 \mathrm{mg} / \mathrm{dl}$. There was no significant age, sex, or admitting diagnosis differences between the. diabetes and nondiabetes groups. Random plasma glucose values varied from 80 to $180 \mathrm{mg} /$ dl. There was no difference in the random plasma glucose values in both categories of patients. Patients with diabetes had higher $\mathrm{HbA}_{1 \mathrm{c}}$ levels than subjects without diabetes. We found that an $\mathrm{HbA}_{1 \mathrm{c}}$ value $=>6.5 \%$ was $100 \%(11 / 11)$ specific for the diagnosis of diabetes.

\section{Discussion}

For many years, blood glucose levels have remained the standard tests for diagnosis of diabetes. Estimating glucose values have problems of collection of a fasting sample. According to $\mathrm{WHO}$, diabetes is diagnosed if the (venous) fasting plasma glucose (FPG) value is $>=126 \mathrm{mg} \mathrm{dl}$, or if the casual plasma glucose value is $>=200 \mathrm{mg} \mathrm{dl}$, or if the plasma glucose value 2 hours after a $75 \mathrm{~g}$ oral load of glucose $>=200 \mathrm{mg}$ dl. Intermediate categories i.e. Impaired fasting glycemia $(>=110$ and $<126 \mathrm{mg} / \mathrm{dl})$ and Impaired Glucose Tolerance (F, 126mg/dl, $>=140 \mathrm{mg} /$ dl). In asymptomatic subjects, performing the test on one occasion is not enough to establish the diagnosis (i.e. basis to treat diabetes). Patient has to come back on another occasion for the test (3).

HbAlc is a simple test for glycated haemoglobin and reflects glycemic control over the last six to eight weeks. International expert committee recommends $\mathrm{A} 1 \mathrm{C}$ assay for the diagnosis of diabetes as it is an accurate, precise measure of chronic glycemic levels and correlates well with the risk of diabetes complications.

Many studies in western literature, have advocated the use of $\mathrm{HbA} 1 \mathrm{c}$ for diagnosis of diabetes $(5,6,7)$. When both FPG and $\mathrm{A} 1 \mathrm{C}$ were measured, a stronger correlation was found between $\mathrm{A} 1 \mathrm{C}$ and retinopathy than between fasting glucose levels and retinopathy (7) Studies that have assessed glycemia with $\mathrm{A} 1 \mathrm{C}$ or with single or longitudinal measurements of glucose levels have consistently demonstrated a strong correlation between retinopathy and $\mathrm{A} 1 \mathrm{C}(8)$.

In our country, patient compliance is a major problem. For plasma glucose testing, patient have to come back on one more occasion, leading to reduced compliance and delay in initiating treatment. Glucose testing has inherent problems of preanalytic errors due to sample handling (9). In this study we minimized the problems by monitored sample collection and immediate analysis.
In this study $\mathrm{HbAlc}$ levels have correlated well with fasting glucose values. In high risk groups this could well become the method of choice for diagnosing diabetes, as it reflects on glucose metabolism over a long period. The $\mathrm{HbA1c}$ level was useful in differentiating between patients with and without diabetes.. Patient compliance may be better if only one sample is taken. HbAlc is a handy test which can help in early diagnosis of diabetes by testing a large number of people. This can be obtained at any time and requires no patient preparation.

We evaluated Hbalc in asymptomatic individuals. Selection of patients was risk based so as to detect maximum patients. We tested admitted patients as it was easier to assess the risk, minimize preanalytical variables and collect the sample. All patients who were diagnosed as diabetics by Fasting Plasma Glucose could be diagnosed by $\mathrm{HbAlc}$.

Limitations of this study were the small sample size. We also did not evaluate the prediabetic state as that was out of the scope of study. Further studies are required to test costeffectiveness of the test for its use in screening of patients.

\section{Conclusion}

This study was aimed at evaluating the utility of $\mathrm{HbAlc}$ in diagnosing diabetes in admitted patients in our hospital. $\mathrm{HbAlc}$ correlated well with fasting plasma glucose values. In clinical settings, this test would be preferred as a first line test for diagnosis of diabetes in our country as it is convenient for the patient. Further large scale studies are required, with evaluation of cost effectiveness to include this as a diagnostic criterion for diagnosis of diabetes.

\section{Reference}

1. H King, R E Aubert, W H Herman. Global burden of diabetes, 1995-2025: prevalence, numerical estimates, and projections.Diabetes Care Sep 1998 vol. 21 no. 9 1414-1431

2. Ramachandran, C. Snehalatha And Vijay Viswanathan. Burden Of Type 2 Diabetes And Its Complications -The Indian Scenario. Current Science, Vol. 83, No. 12, 25 Dec 2002.

3. World Health Organization. Definition, Diagnosis and Classification of Diabetes Mellitus and its Complications. Report of a WHO Consultation. Geneva: World Health Organization, 1999.

4. International Expert Committee. Report on the Role of the A1C Assay in the Diagnosis of Diabetes. Diabetes Care July 2009 Vol. 32 No. 7 1327-1334.

5. Zhong X. Lu, Karen Z. Walker, Kerin O’Dea, Ken A. Sikaris, Jonathan E. Shaw. A1C for Screening and Diagnosis of Type 2 Diabetes in Routine Clinical Practice. Diabetes Care April 2010 vol. 33 no. 4 817-819. 
6. Ko GT, Chan JC, Tsang LW, Cockram CS.Combined use of fasting plasma glucose and $\mathrm{HbA1c}$ predicts the progression to diabetes in Chinese subjects. Diabetes Care 2000 Dec; 23(12):1770-3.

7. Tapp RJ, Tikellis G, Wong TY,Harper C, Zimmet PZ, Shaw JE. Longitudinal association of glucose metabolism with retinopathy. Diabetes Care 2008; 31: 1349- 1354.
8. Relationship between glycated hemoglobin and microvascular complications: is there a natural cut-off point for the diagnosis of diabetes. Diabetologia. 2242009.

9. Murphy JM, Browne RW, Hill L, Bolelli GF, Abagnato C, Berrino F, Freudenheim J, Trevisan M, Muti P. Effects of transportation and delay in processing on the stability of nutritional and metabolic biomarkers. Nutr Cancer 2000; 37: 155- 160

*Corresponding author:

Col (Dr) Jagdeep Singh Bhatia, Senior Advisor Anaesthesia, Command Hospital, Southern Command, Pune, India.

Phone: +91 9888871541

Email: drjsbhatia@gmail.com

Financial or other Competing Interests: None. 